www.nature.com/pj

\title{
Optically active polyurethane based on tyrosine: synthesis, characterization and study of hydrogen bonding
}

\author{
Yong Yang ${ }^{1}$, Chen Sun ${ }^{1}$, Yuming Zhou ${ }^{2}$, Tianhe Wang ${ }^{1}$ and Yiwei Zhang ${ }^{2}$ \\ Optically active polyurethane (OPU) and racemic polyurethane (RPU) derived from chiral and racemic tyrosine were synthesized \\ using a hydrogen transfer addition polymerization procedure. The structural and optical properties of the polyurethanes were \\ systematically investigated using Fourier transform infrared spectroscopy, ${ }^{1} \mathrm{H}$ NMR, gel permeation chromatography (GPC), UV-vis \\ spectroscopy, circular dichroism spectroscopy, thermogravimetric analysis (TGA) and X-ray diffraction techniques. In contrast to \\ RPU, OPU possesses a single-handed helical conformation and optical activity owing to the induced asymmetric force field in \\ the chiral monomer. This regular secondary structure facilitates the formation of numerous interchain hydrogen bonds, which \\ increases the crystallinity and thermal stability of OPU. The high-temperature infrared spectroscopy results indicate that the \\ hydrogen bonding collapses before thermal decomposition. In contrast to the intense infrared emissivity property of random \\ coiled RPU, both helical stereostructures and hydrogen bonding contribute to decreasing this emissivity for OPU. \\ Polymer Journal (2016) 48, 807-812; doi:10.1038/pj.2016.33; published online 16 March 2016
}

\section{INTRODUCTION}

Optically active polymers, which are known as helical polymers or chiral polymers that are characterized by an extended one-handed helical conformation along the macromolecular backbone, have emerged as a group of advanced materials owing to their regular secondary structure. These functional polymers are of great scientific and technological importance because of their adjustable chiral parameters, abundant interchain interactions and stimuli responsive properties. ${ }^{1-4}$ Among these characteristics, the appropriate arrangement of intermolecular and intramolecular noncovalent interactions, especially hydrogen bonds, determine the formation and stability of the helical configuration. Biological macromolecules, such as DNA and proteins, are stabilized by hydrogen bonds. Moreover, the significant effects of hydrogen bonding in many artificial helical polymers (for example, polyolefins, ${ }^{5}$ polyacetylenes, ${ }^{6}$ polymethacrylamides $^{7}$ and polyanilines ${ }^{8}$ ) have been previously investigated. When the hydrogen bonds are well organized, an increase in the rigidity of the main chains and the absolute value of the specific rotations can be observed, indicating promotion of helical architectures.

Polyurethanes (PUs) have been widely employed in nearly every aspect of daily life including construction, microelectronics, biomedical engineering and light industry owing to their abrasive resistance, outstanding mechanical properties and excellent chemical stability. ${ }^{9,10}$ As an important class of thermoplastic and thermoset polymers, PUs combine high elasticity and strength, which can be tailored by tuning the distribution of soft and hard segments. Therefore, the introduction of chirality in PUs is important to researchers. Qiu et al. ${ }^{11}$ prepared an azobenzene-containing optically active PU and investigated its thermo-optic coefficients. The asymmetry induced by the chiral factor enhances the sensitivities of the refractive index of polymeric material, which is crucial for optical switch applications. Sreekumar et al. ${ }^{12}$ synthesized a series of optically active PUs based on diethyl-(2R,3R) (+)-tartrate, and these polymers exhibited good thermal stabilities and insulating characteristics. We have reported the self-polyaddition of isocyanate-phenols based on the tyrosine hexyl ester. ${ }^{13}$ The orderly helical secondary structure and hydrogen bonding in optically active PUs decreased their infrared emissivity, and these PUs have potential for applications in the military and thermal insulation. The solvent resistance of the film for coating applications needs to be improved.

Herein, a chiral bisphenol monomer of N-(4-hydroxylbenzoyl)-Ltyrosine hexyl ester based on tyrosine was synthesized and polymerized with 4,4'-diphenyl methane diisocyanate (MDI) using hydrogen transfer addition polymerization. The obtained PU exhibited good solvent resistance because of the introduction of more hard segments. The optically active polyurethane (OPU) possesses a one-handed helical structure compared with the racemic polyurethane (RPU) based on DL-tyrosine. The effect of incorporation of chirality on the crystallinity as well as the thermal stability associated with hydrogen bonding have been investigated. Moreover, the infrared emissivity property of the PUs was investigated, which may provide insight into

\footnotetext{
${ }^{1}$ Key Laboratory of Soft Chemistry and Functional Materials, Ministry of Education, Nanjing University of Science and Technology, Nanjing, China and ${ }^{2}$ School of Chemistry and Chemical Engineering, Southeast University, Nanjing, China

Correspondence: Dr Y Yang, Key Laboratory of Soft Chemistry and Functional Materials, Ministry of Education, Nanjing University of Science and Technology, 200 Xiaolingwei, Xuanwu District, Nanjing, Jiangsu 210094, China.

E-mail: yw6729@163.com

Received 14 April 2015; revised 15 January 2016; accepted 20 January 2016; published online 16 March 2016
} 
the development of a practical coating material for low infrared emissivity.

\section{EXPERIMENTAL PROCEDURE}

\section{Materials}

L-Tyrosine, DL-tyrosine, thionyl chloride and triethylamine were purchased from Sinopharm Chemical Reagent Co., Ltd (Shanghai, China). 4-Hydroxybenzoic acid was supplied by Sigma-Aldrich Shanghai Trading Co., Ltd (Shanghai, China) and 1-ethyl-3-(3-dimethyllaminopropyl)carbodiimide hydrochloride (EDC.HCl), o-tolyl isocyanate and p-tolyl isocyanate were obtained from Aladdin (Shanghai, China). MDI was obtained from Acros Organics (Geel, Belgium). Citric acid, sodium carbonate, sodium chloride and magnesium sulphate were purchased from commercial sources and used as received without further purification. 1-Hexanol as well as the other solvents were obtained from Sinopharm Chemical Reagent Co., Ltd and distilled before use.

\section{Measurements}

The melting point $(\mathrm{mp})$ was measured using an X-4 micro-melting point apparatus. The Fourier transform infrared (FTIR) spectra and hightemperature FTIR spectra were obtained on a Bruker Tensor 27 FTIR spectrometer using $\mathrm{KBr}$ pellets. The temperature of the sample was controlled using a Watlow's series 988 controller at a heating rate of $5 \mathrm{~K}$ per min. The spectra were obtained at a resolution of $4 \mathrm{~cm}^{-1}$ in the $4000-400 \mathrm{~cm}^{-1}$ region. The ${ }^{1} \mathrm{H}$ NMR spectra measurements were recorded on a Bruker AVANCE $300 \mathrm{MHz}$ NMR spectrometer. The chemical shifts were reported in p.p.m. The optical rotation of all of the samples was measured using a WZZ-2S (2SS) digital automatic polarimeter at room temperature. The wavelength of the sodium lamp was $589.44 \mathrm{~nm}$. The molecular weights and molecular weight polydispersities were determined by gel permeation chromatography (GPC) (Shodex KF-850 column), which was calibrated using polymethylmethacrylate (PMMA) with dimethylformamide (DMF) as the eluent at $80^{\circ} \mathrm{C}$. The UV-vis spectra of the samples in solution were measured on a Shimadzu UV 3600 spectrometer. The CD spectra were determined with a Jasco J-810 spectropolarimeter using a $10-\mathrm{mm}$ quartz cell at room temperature. The X-ray diffraction (XRD) measurements were recorded using a Rigaku D/MAX-R with a copper target at $40 \mathrm{kV}$ and $30 \mathrm{~mA}$. The powder samples were spread on a sample holder, and the diffractograms were recorded from $5^{\circ}$ to $80^{\circ}$ at a rate of $5^{\circ}$ per min. Thermal analysis experiments were performed using a thermogravimetric analysis (TGA) apparatus operated in the conventional TGA mode
(TA Q-600, TA Instruments) at a heating rate of $10 \mathrm{~K}$ per min in a nitrogen atmosphere, and the sample size was $\sim 50 \mathrm{mg}$. The infrared emissivity values of the samples were investigated using an IRE-I Infrared Emissometer manufactured by the Shanghai Institute of Technology and Physics, China.

\section{Synthesis of monomers and polyurethanes}

Synthesis of L-tyrosine hexyl ester. L-Tyrosine hexyl ester hydrochloride was prepared using the thionyl chloride technique. ${ }^{14}$ The $\mathrm{HCl}$ salt of the tyrosine hexyl ester was dissolved in deionized water followed by neutralization of the solution with $\mathrm{Na}_{2} \mathrm{CO}_{3}$ until the $\mathrm{pH}$ of the aqueous phase was $\sim 10$. Then, $3 \mathrm{vol}$ of ethyl ether was added, and the free base was extracted into the organic layer, which was separated from the aqueous layer. The organic layer was washed with a saturated $\mathrm{NaCl}$ solution, dried over $\mathrm{MgSO}_{4}$ and evaporated to dryness under reduced pressure to yield a white powder (that is, L-tyrosine hexyl ester). DL-tyrosine hexyl ester was prepared in a similar fashion using DL-tyrosine rather than L-tyrosine.

L-Tyrosine hexyl ester: Yield $87 \%$, white solid, $\mathrm{mp} 65-66^{\circ} \mathrm{C} ;[\alpha]_{\mathrm{D}}^{25}=+10.4^{\circ}$ ( $\mathrm{c}=5 \mathrm{~g} \mathrm{dl}^{-1}$, ethyl ether). ${ }^{1} \mathrm{H} \mathrm{NMR}\left(300 \mathrm{MHz}, \mathrm{CDCl}_{3}\right): \delta 0.90(\mathrm{t}, J=6.18 \mathrm{~Hz}$, $\left.3 \mathrm{H},-\mathrm{CH}_{3}\right), 1.31\left(\mathrm{~m}, 6 \mathrm{H},-\mathrm{CH}_{2^{-}}\right), 1.64\left(\mathrm{~m}, 2 \mathrm{H},-\mathrm{CH}_{2-}\right), 2.79-3.08(\mathrm{~m}, 2 \mathrm{H}$, $\left.-\mathrm{PhCH}_{2}-\right), 3.73(\mathrm{t}, J=6.49 \mathrm{~Hz}, 1 \mathrm{H},>\mathrm{CH}-), 3.78\left(\mathrm{~s}, 2 \mathrm{H},-\mathrm{NH}_{2}\right), 4.11-4.15$ (t, J=6.06 Hz, 2H, $\left.-\mathrm{OCH}_{2^{-}}\right), 6.65-7.01\left(\mathrm{~m}, 4 \mathrm{H},-\mathrm{C}_{6} \mathrm{H}_{4^{-}}\right)$. FTIR $\left(\mathrm{v} / \mathrm{cm}^{-1}\right): 3356$ $(\mathrm{O}-\mathrm{H}), 3296(\mathrm{~N}-\mathrm{H}), 2962,2858,1734(\mathrm{C}=\mathrm{O}), 1516,1252,1188,825$.

DL-Tyrosine hexyl ester: Yield $89 \%$, white solid, mp $46-47^{\circ} \mathrm{C} ;[\alpha]^{25} \mathrm{D}=0^{\circ}$ ( $c=5 \mathrm{~g} \mathrm{dl}^{-1}$, ethyl ether). The ${ }^{1} \mathrm{H} \mathrm{NMR}$ and IR data of this ester are similar to those of L-tyrosine hexyl ester and have been omitted.

Synthesis of N-(4-hydroxylbenzoyl)-L-tyrosine hexyl ester. In total, $2.4 \mathrm{~g}$ of L-tyrosine hexyl ester and $1.25 \mathrm{~g}$ of 4-hydroxybenzoic acid were placed in a three-neck round-bottom flask and dissolved in $30 \mathrm{ml}$ of tetrahydrofuran (THF). The mixture was chilled in an ice bath for $30 \mathrm{~min}$. Then, $1.92 \mathrm{~g}$ of EDC. $\mathrm{HCl}$ was added. The reaction mixture was stirred for $1 \mathrm{~h}$ in an ice bath and $24 \mathrm{~h}$ at room temperature. The resulting mixture was poured into $500 \mathrm{ml}$ of deionized water to yield an oil. Then, $30 \mathrm{ml}$ of $\mathrm{CH}_{2} \mathrm{Cl}_{2}$ was added, and the product was extracted. The organic phase was washed consecutively with $0.1 \mathrm{M}$ $\mathrm{Na}_{2} \mathrm{CO}_{3}, 0.1 \mathrm{M}$ citric acid and saturated $\mathrm{NaCl}$ followed by drying over $\mathrm{MgSO}_{4}$. The product was purified by column chromatography using petroleum ether/ ethyl acetate $(3 / 1, \mathrm{v} / \mathrm{v})$ as the eluent to obtain $1.61 \mathrm{~g}$ of $\mathrm{N}$-(4-hydroxylbenzoyl)L-tyrosine hexyl ester as a white solid.

$\mathrm{N}$-(4-hydroxylbenzoyl)-L-tyrosine hexyl ester: Yield 46\%, white solid, mp $112-113^{\circ} \mathrm{C} ;[\alpha]^{25}=+11.1^{\circ}\left(\mathrm{c}=5 \mathrm{~g} \mathrm{dl}^{-1}\right.$, ethyl acetate). ${ }^{1} \mathrm{H}$ NMR $(300 \mathrm{MHz}$, DMSO- $\left.\mathrm{d}_{6}\right): \delta 0.82\left(\mathrm{t}, J=6.92 \mathrm{~Hz}, 3 \mathrm{H},-\mathrm{CH}_{3}\right), 1.20-1.28\left(\mathrm{~m}, 6 \mathrm{H},-\mathrm{CH}_{2}-\right), 1.47$
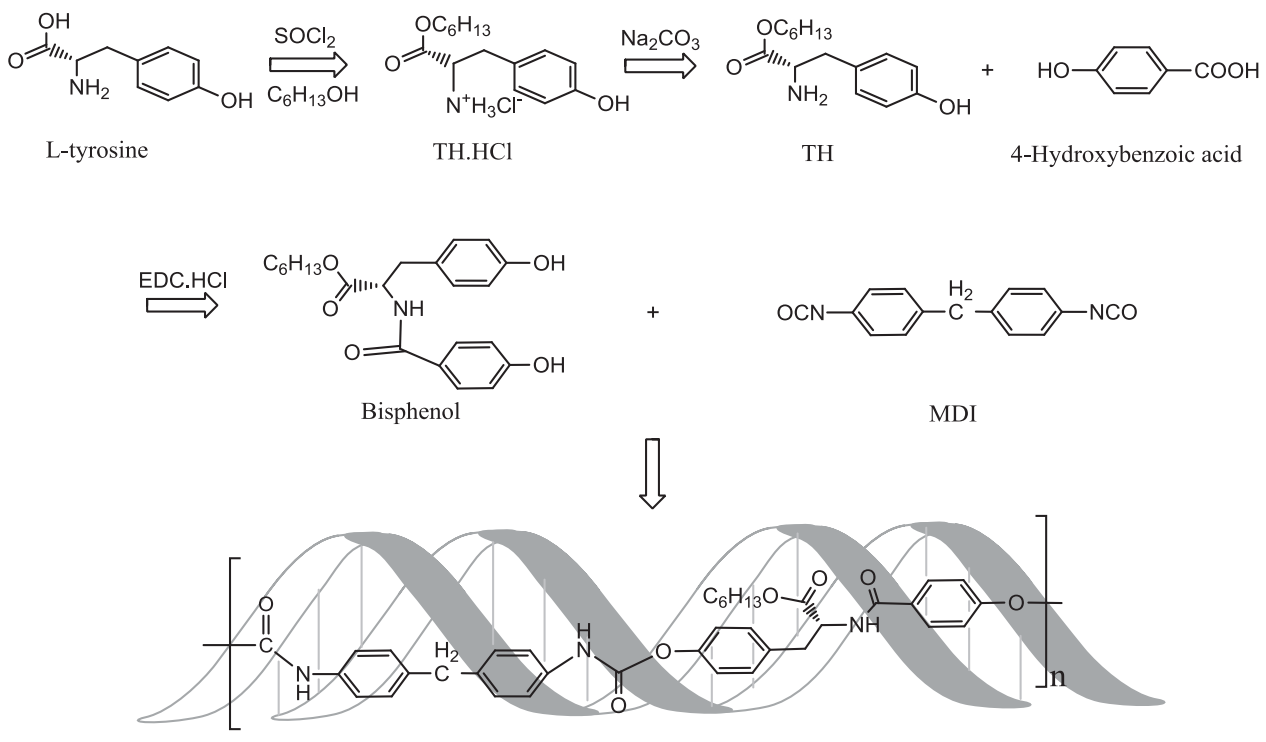

Optically active polyurethane

Figure 1 Synthetic procedure for $\mathrm{N}$-(4-hydroxylbenzoyl)-L-tyrosine hexyl ester and optically active polyurethane. A full color version of this figure is available at Polymer Journal online. 
$\left(\mathrm{m}, 2 \mathrm{H},-\mathrm{CH}_{2^{-}}\right), 2.95-2.98\left(\mathrm{~m}, 2 \mathrm{H},-\mathrm{PhCH}_{2}-\right), 3.99\left(\mathrm{t}, J=7.35 \mathrm{~Hz}, 2 \mathrm{H},-\mathrm{OCH}_{2^{-}}\right)$, $4.46-4.49(\mathrm{t}, J=7.17 \mathrm{~Hz}, 1 \mathrm{H},>\mathrm{CH}-), 6.62-7.70\left(\mathrm{~m}, 8 \mathrm{H},-\mathrm{C}_{6} \mathrm{H}_{4^{-}}\right), 8.48-8.51$ (d, $1 \mathrm{H},-\mathrm{NH}-), 9.21(\mathrm{~s}, 1 \mathrm{H},-\mathrm{OH}), 10.02(\mathrm{~s}, 1 \mathrm{H},-\mathrm{OH})$. FTIR $\left(\nu \mathrm{cm}^{-1}\right): 3444$ (O-H), 3327 (N-H), 2948, 2920, 2853, 1723 (C=O), 1637, 1506, 1230, 847.

$\mathrm{N}$-(4-hydroxylbenzoyl)-DL-tyrosine hexyl ester. Yield 49\%, white solid, mp ${ }^{132-134}{ }^{\circ} \mathrm{C} ;[\alpha]^{25}=0^{\circ}\left(\mathrm{c}=5 \mathrm{~g} \mathrm{dl}^{-1}\right.$, ethyl acetate). The ${ }^{1} \mathrm{H}$ NMR and IR data of $\mathrm{N}$-(4-hydroxylbenzoyl)-DL-tyrosine hexyl ester are similar to those of $\mathrm{N}$-(4-hydroxylbenzoyl)-L-tyrosine hexyl ester and have been omitted.

Synthesis of polyurethanes. In total, $0.385 \mathrm{~g}$ of $\mathrm{N}$-(4-hydroxylbenzoyl)L-tyrosine hexyl ester was dissolved in $30 \mathrm{ml}$ DMF followed by heating to $70{ }^{\circ} \mathrm{C}$ in a nitrogen atmosphere. Subsequently, $0.25 \mathrm{~g}$ of MDI, dissolved in $20 \mathrm{ml}$ of DMF, was dropped slowly into the above solution. Then, the reaction was conducted for $2 \mathrm{~h}$ and heated to $120^{\circ} \mathrm{C}$ for $24 \mathrm{~h}$. The resulting mixture was cooled and poured into ethyl acetate to precipitate the OPU as a yellow solid. The racemic polyurethane (RPU) was prepared in a similar fashion using $\mathrm{N}$-(4-hydroxylbenzoyl)-DL-tyrosine hexyl ester. The preparation process is shown in Figure 1.

The spectroscopic data for the PUs are as follows (using OPU as an example): ${ }^{1} \mathrm{H}$ NMR (DMSO-d $\left.\mathrm{d}_{6}\right) \delta: 0.83\left(3 \mathrm{H},-\mathrm{CH}_{3}\right), 1.21-1.33\left(6 \mathrm{H},-\mathrm{CH}_{2}-\right)$, 1.41-1.47 (2H, $\left.-\mathrm{CH}_{2}-\right), 2.72-2.88\left(2 \mathrm{H},-\mathrm{PhCH}_{2}-\right), 3.51 \quad\left(2 \mathrm{H},-\mathrm{OCH}_{2}-\right)$, $3.78-3.87\left(2 \mathrm{H},-\mathrm{CH}_{2}-\right), 4.01(1 \mathrm{H},>\mathrm{CH}-), 6.64-7.66\left(16 \mathrm{H},-\mathrm{C}_{6} \mathrm{H}_{4}-\right), 7.96$ $(1 \mathrm{H},-\mathrm{C}(\mathrm{O}) \mathrm{NH}-), 8.53(2 \mathrm{H},-\mathrm{OC}(\mathrm{O}) \mathrm{NH}-)$. FTIR $\left(\nu \mathrm{cm}^{-1}\right)$ : 3296, 3030, 2897, 2930, $1643\left(-\mathrm{CO}_{2} \mathrm{C}_{6} \mathrm{H}_{13},-\mathrm{C}(\mathrm{O}) \mathrm{NH}-,-\mathrm{OC}(\mathrm{O}) \mathrm{NH}-\right), 1593,1508,1408,1301$, $1232,1016,808,638,501$.

\section{Synthesis of model urethane compound}

In total, $0.385 \mathrm{~g}$ of $\mathrm{N}$-(4-hydroxylbenzoyl)-L-tyrosine hexyl ester was dissolved in $30 \mathrm{ml}$ of toluene followed by heating to $100^{\circ} \mathrm{C}$ in a nitrogen atmosphere. An amount of $0.292 \mathrm{~g}$ of p-tolyl isocyanate was dissolved in $20 \mathrm{ml}$ of toluene, and this solution was slowly added dropwise to the above solution followed by refluxing for $3 \mathrm{~h}$. Then, the mixture was cooled to room temperature and reacted for an additional $24 \mathrm{~h}$ using TEA as the catalyst. The resulting mixture was evaporated to yield a pale yellow oil as the crude product, and this product was purified by column chromatography using petroleum ether/ethyl acetate $(3 / 2, \mathrm{v} / \mathrm{v})$ as the eluent to yield $0.139 \mathrm{~g}$ of model urethane compound (MUC). The structure of MUC is shown in Figure 2.

MUC. Yield $22 \%$, white solid, $\mathrm{mp} 127-129^{\circ} \mathrm{C} ;[\alpha]_{\mathrm{D}}^{25}=-46.2^{\circ}\left(\mathrm{c}=5 \mathrm{~g} \mathrm{dl}^{-1}\right.$, DMF). ${ }^{1} \mathrm{H}$ NMR $\left(300 \mathrm{MHz}, \mathrm{CDCl}_{3}\right): \delta 0.98\left(\mathrm{t}, J=6.3 \mathrm{~Hz}, 3 \mathrm{H},-\mathrm{CH}_{3}\right), 1.41$ $\left(\mathrm{m}, 6 \mathrm{H},-\mathrm{CH}_{2}-\right), 1.74\left(\mathrm{~m}, 2 \mathrm{H},-\mathrm{CH}_{2}{ }^{-}\right), 2.42\left(\mathrm{~s}, 3 \mathrm{H},-\mathrm{PhCH}_{3}\right), 2.43(\mathrm{~s}, 3 \mathrm{H}$, $\left.-\mathrm{PhCH}_{3}\right), 3.34-3.39\left(\mathrm{~m}, 2 \mathrm{H},-\mathrm{PhCH}_{2^{-}}\right), 4.25-4.26\left(\mathrm{t}, J=6.9 \mathrm{~Hz}, 2 \mathrm{H},-\mathrm{OCH}_{2^{-}}\right)$, $5.16-5.18(\mathrm{t}, J=6.9 \mathrm{~Hz}, 1 \mathrm{H},>\mathrm{CH}-), 6.72-6.74(\mathrm{~d}, J=7.2 \mathrm{~Hz}, 1 \mathrm{H},-\mathrm{C}(\mathrm{O}) \mathrm{NH}-)$, 7.04-7.45 (m, 16H, $\left.-\mathrm{C}_{6} \mathrm{H}_{4^{-}}\right), 7.86(\mathrm{~s}, 1 \mathrm{H},-\mathrm{OC}(\mathrm{O}) \mathrm{NH}-), 7.88(\mathrm{~s}, 1 \mathrm{H},-\mathrm{OC}(\mathrm{O})$ NH-). FTIR $\left(\nu \mathrm{cm}^{-1}\right): 3307(\mathrm{~N}-\mathrm{H}), 2954,2926,2858,1713(\mathrm{C}=\mathrm{O}), 1497$, $1195,1016,814$

\section{RESULTS AND DISCUSSION}

\section{FTIR and NMR analyses of OPU and RPU}

The FTIR spectra of OPU and RPU are shown in Figure 3. Both OPU and RPU have nearly the same absorptions. The peaks of amide I and amide II located at 1643 and $1545 \mathrm{~cm}^{-1}$ were assigned to stretching vibrations of the carbonyl groups and bending vibrations of $\mathrm{N}-\mathrm{H}$, respectively. The band at $1232 \mathrm{~cm}^{-1}$ was assigned to stretching vibrations of the $\mathrm{C}-\mathrm{N}$ groups for amide III. Moreover, the characteristic band at $2259 \mathrm{~cm}^{-1}$ corresponding to the $\mathrm{N}=\mathrm{C}=\mathrm{O}$ group

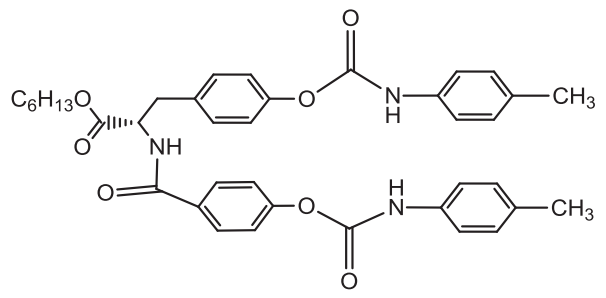

Figure 2 Model urethane compound. disappeared, which indicates that the polymerization was successful. Table 1 summarizes the results of the polymerization. Polyurethanes with narrow molecular weight distributions were obtained. However, the molecular weights of these polyurethanes were low, which may be due to the very dilute reaction systems. Furthermore, two phenolic hydroxy groups exhibited different nucleophilicities based on the asymmetric structure of the bisphenol. The slow addition of MDI may have lead to the head-to-head (tail-to-tail) polymerization, which resulted in the formation of cyclic urethane oligomers. Therefore, a control experiment was conducted by reacting bisphenol with two molecules of o-tolyl isocyanate. However, only one phenolic hydroxy group reacted with o-tolyl isocyanate (Supplementary Figure S1, Supporting Information (SI)). The inertness of the other hydroxyl group influenced by the carbonyl and benzene ring hindered its reactivity. However, as shown in the ${ }^{1} \mathrm{H}$ NMR (Supplementary Figure S2, Supporting Information (SI)) of the product, both of the phenolic hydroxyl groups reacted simultaneously with the p-tolyl isocyanate when an equimolar amount of $\mathrm{p}$-tolyl isocyanate was used. Unexpectedly, the activities of the hydroxyl groups did not exhibit differences. Based on the GPC results, head-to-head (tail-to-tail) polymerization did not occur in the early period of the reaction between bisphenol and MDI. As the reaction proceeded, cyclic urethanes were formed owing to the slow addition of MDI and the very dilute reaction system.

It is important to note that the IR absorptions that ranged from 3500 to $3200 \mathrm{~cm}^{-1}$, which corresponded to stretching vibrations of the $\mathrm{N}-\mathrm{H}$ groups, exhibited significant differences. The participation in hydrogen bonds will decrease the frequency of absorptions and increase their intensity. ${ }^{15,16}$ The band for the $\mathrm{N}-\mathrm{H}$ groups splits into two peaks at 3390 and $3296 \mathrm{~cm}^{-1}$, which correspond to free and hydrogen bonded N-H groups, respectively, for RPU. However, OPU primarily has hydrogen-bonded $\mathrm{N}-\mathrm{H}$ groups. In addition, the region of carbonyl absorptions undergoes a similar variation. Despite the overlap between the carbonyls belonging to the ester and amide, the red shift was still observed. The formation of hydrogen bonds was investigated using ${ }^{1} \mathrm{H}$ NMR spectrum, which result in the peaks of corresponding the protons shifting to a lower field. As shown in Figure 4, the N-H protons that belong to amide and urethane in RPU were observed at $\sim 7.95$ and 8.52 p.p.m., respectively. For OPU, the two types of signals shifted to a lower field. Although the hydrogen bonding may be destroyed in many highly polar solvents, such as

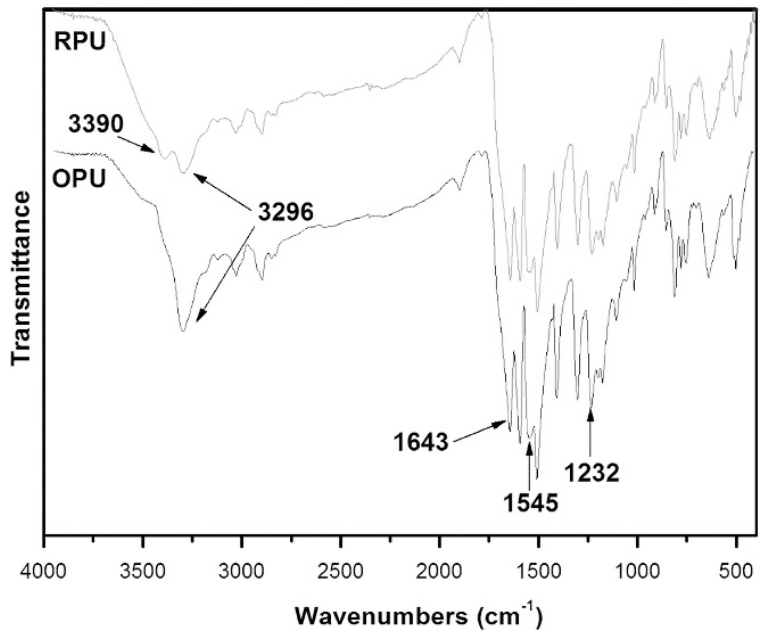

Figure 3 FTIR spectra of RPU and OPU. A full color version of this figure is available at Polymer Journal online. 
Table 1 Polymerization results and characterization of PUs

\begin{tabular}{lcccc}
\hline Polymer & Yield $^{\mathrm{a}(\%)}$ & $\mathrm{M}_{n}{ }^{\mathrm{b}}$ & $\mathrm{M}_{w} / \mathrm{M}_{n}{ }^{\mathrm{b}}$ & {$[\alpha]_{\mathrm{D}}^{25}{ }^{\mathrm{c}}$} \\
\hline OPU & 43 & 5849 & 1.49 & $-65.0 \pm 5$ \\
RPU & 46 & 6160 & 1.42 & 0
\end{tabular}

Abbreviations: OPU, optically active polyurethane; RPU, racemic polyurethane.

aEthyl acetate-insoluble part.

${ }^{\text {b}}$ Determined by GPC eluted with DMF based on polymethylmethacrylate (PMMA) standards.

${ }^{\mathrm{c}}$ Measured by polarimetry at room temperature, $c=0.008 \mathrm{~g} \mathrm{dl}^{-1}$ in DMF.

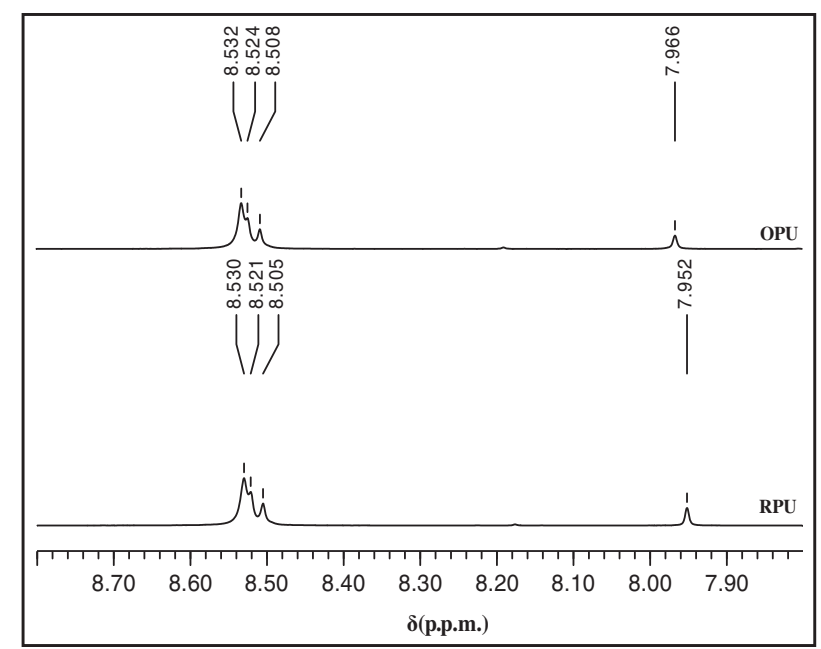

Figure $4{ }^{1} \mathrm{H}$ NMR spectra of RPU and OPU in $\mathrm{d}_{6}$-DMSO at 7.80-8.80 p.p.m.

DMSO, the variations between OPU and RPU can still be observed. Both the IR and NMR results indicate that the degree of hydrogen bonding in OPU is higher than that in RPU, and the introduction of chirality in the polymer results in an orderly secondary structure that facilitates the formation of hydrogen bonds.

\section{Solubility investigation}

The solubility of the PUs was investigated using various polar and nonpolar solvents, as listed in Table 2. OPU and RPU were solubile in a few polar solvents, such as dimethyl sulfoxide and DMF. However, the polymers were insoluble in tetrahydrofuran, $\mathrm{CHCl}_{3}$ and $\mathrm{H}_{2} \mathrm{O}$. The excellent solvent resistance of the PUs may be due to the presence of hard segments in the main chains.

Optical activity and secondary structure of the polymers

The secondary structure of the polymers can be investigated based on the optical activity and circular dichroism (CD) spectrum. The specific rotation and $\mathrm{CD}$ absorption are detected when excess single-handed helical conformations exist. As summarized in Table 1, OPU exhibited a specific rotation of $-65.0^{\circ}$ in DMF at room temperature, but the corresponding bisphenol monomer exhibited a specific rotation of $+11.1^{\circ}$. The significant difference implied that the optical activity of OPU might originate from the helical secondary structure of the macromolecular chains but not from the monomer. This result requires confirmation by comparison with the corresponding model urethane compound. Moreover, the rotation value of OPU was not very large, which is common in many of the polymers produced by polycondensations. ${ }^{17-19}$ This low value may arise from dispersion of the chiral centers as well as the rigid main chains. In contrast, the specific rotation of RPU was $0^{\circ}$, which is indicative of a random coiled structure for macromolecules.
Table 2 Solubility of OPU and RPU in various solvents

\begin{tabular}{lcc}
\hline Solvent & OPU & $R P U$ \\
\hline DMSO & + & + \\
DMF & + & + \\
DMAc & + & + \\
$\mathrm{NMP}$ & + & + \\
THF & - & - \\
Acetone & - & - \\
$\mathrm{CH}_{3} \mathrm{CN}$ & - & - \\
$\mathrm{CHCl}_{3}$ & - & - \\
$\mathrm{CH}_{2} \mathrm{Cl}_{2}$ & - & - \\
$\mathrm{H}_{2} \mathrm{O}$ & - & - \\
\hline
\end{tabular}

+ , soluble; -, insoluble.
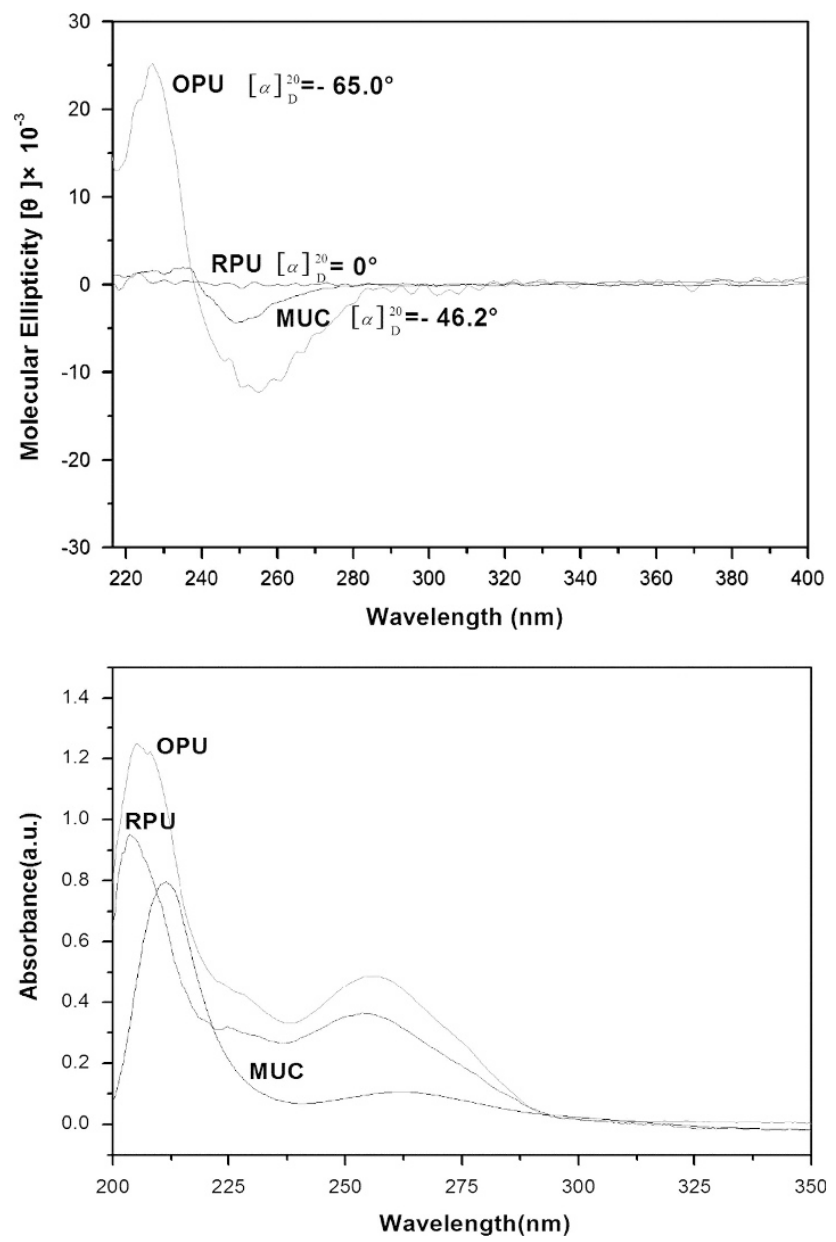

Figure $5 \mathrm{CD}$ and UV-vis spectra of OPU, RPU and MUC measured in ethanol $\left(c=0.008 \mathrm{~g} \mathrm{dl}^{-1}\right)$ at room temperature. A full color version of this figure is available at Polymer Journal online.

Figure 5 shows the $\mathrm{CD}$ and UV-vis spectra of OPU and RPU measured in ethanol at room temperature. In addition, MUC was also characterized for comparison. The polymers and MUC exhibit similar UV-vis absorptions. The peak located at $\sim 230 \mathrm{~nm}$ corresponded to the $\pi-\pi^{\star}$ transition of the aromatic rings, and the broad band centered at $250 \mathrm{~nm}$ was assigned to the $\mathrm{n}-\pi^{*}$ transition of the carbonyl groups. CD spectroscopic analysis is vital for investigating the secondary structure. Therefore, $\mathrm{CD}$ spectroscopy was performed to 


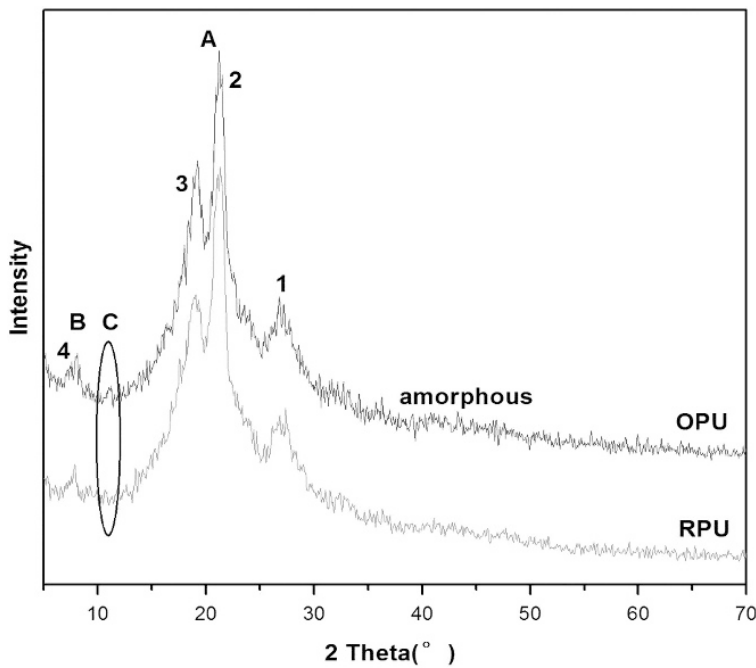

Figure 6 XRD patterns for OPU and RPU. A full color version of this figure is available at Polymer Journal online.

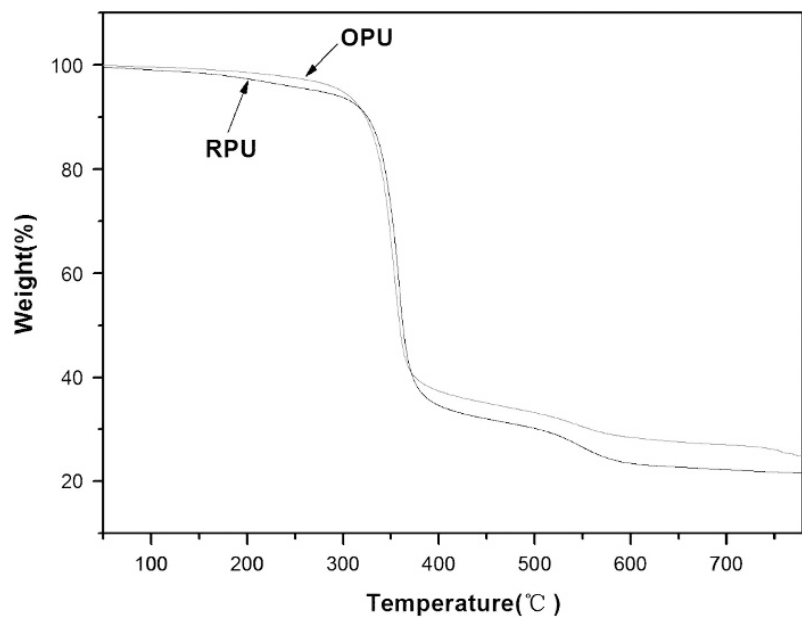

Figure 7 TGA curves of OPU and RPU. A full color version of this figure is available at Polymer Journal online.

confirm the helicity of OPU. The optical rotation and CD spectrum of a polymer would be very close to those of its monomeric model compound when the macromolecular chain does not have a propagating helical conformation. Each unit in the polymer acts independently without an organized synergistic action. ${ }^{20} \mathrm{~A}$ typical Cotton effect was observed at 230 and $250 \mathrm{~nm}$ for OPU. However, the specific rotation and CD spectrum of MUC exhibit large differences. Both results further demonstrate that a helical main chain formed in OPU. In addition, the polyurethane derived from D-tyrosine exhibited the opposite Cotton effect, mirroring that of OPU (Supplementary Figure S3, Supporting Information (SI)). Polyurethanes based on L-tyrosine and D-tyrosine are enantiomorphs that have left-handed and right-handed helical conformations, respectively, with a preferred screw sense. The RPU based on DL-tyrosine exhibited no CD signals, which indicated random coiled molecular chains.

\section{Crystallinity and thermal stability properties}

The wide-angle X-ray diffractograms for the polymers are show in Figure 6. Based on the diffraction patterns for OPU and RPU, the two main crystalline regions (A and B) can be divided into 1, 2, 3 and 4
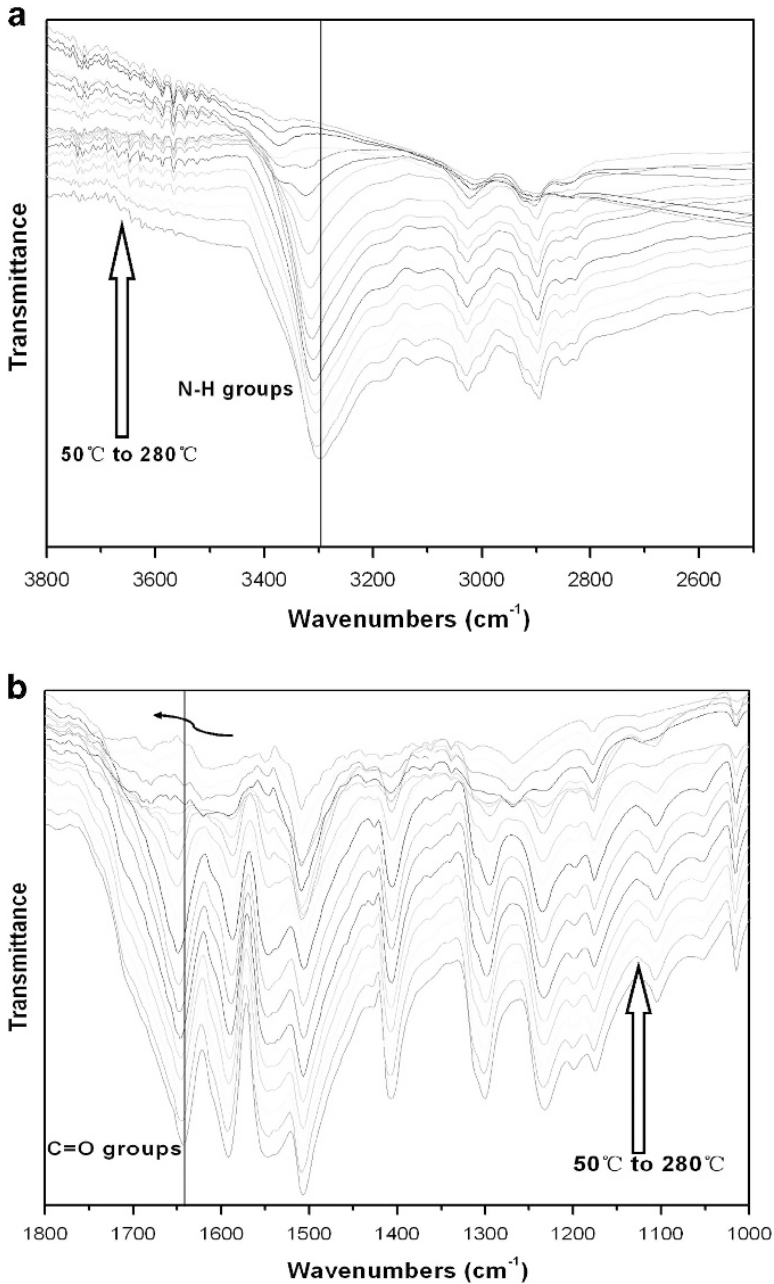

Figure 8 High-temperature FTIR spectra of OPU at (a) $3800-2500 \mathrm{~cm}^{-1}$ and (b) $1800-1000 \mathrm{~cm}^{-1}$. A full color version of this figure is available at Polymer Journal online.

Table 3 Infrared emissivity values of samples

\begin{tabular}{lc}
\hline Samples & Infrared emissivity $\left(\varepsilon_{T I R}\right.$ at $\left.8-14 \mu \mathrm{m}\right)$ \\
\hline RPU & 0.912 \\
OPU & 0.785 \\
\hline
\end{tabular}

maxima as main peaks and amorphous regions. The peaks at $2 \theta=19.2^{\circ}$ and $21.2^{\circ}$, which overlap with the A region, are consistent with the literature values for MDI and tyrosine crystallinity. ${ }^{13,21}$ The other peaks may be due to the 4-hydroxybenzoic acid and the new segments generated during the polymerization. It is important to note that crystalline peak $\mathrm{C}$ appears at $\sim 12^{\circ}$ for the optically active OPU. Both polymers with the same composition were obtained using the hydrogen transfer addition polymerization procedure with bisphenol and MDI. No other ingredients can produce crystallinity. Therefore, the introduction of orderliness as well as optical activity by virtue of the regular helical secondary structure in the molecular chain induced by the chiral center resulted in higher crystallinity in this new region. However, the diffraction peak was not intense, which may be due to the low content of helical secondary structures in the macromolecules with rigid main chains and flexible pendant groups. In addition, the random coiled macromolecular chains of RPU, which are based on the 
racemic monomer, were confirmed, which is consistent with the $\mathrm{CD}$ analysis.

The thermal properties of OPU and RPU were investigated using TGA techniques at a heating rate of $10^{\circ} \mathrm{C}$ per min under a nitrogen atmosphere. As shown in Figure 7, the TGA curve for each sample exhibited a smooth, stepwise manner, suggesting a two-step thermal degradation. The optically active polymer has a higher thermal stability than that of the racemic one, and the temperature of the $5 \%$ weight loss $\left(\mathrm{T}_{5}\right)$ of OPU and RPU were $280^{\circ} \mathrm{C}$ and $273{ }^{\circ} \mathrm{C}$, respectively, which may be due to their different chain conformations. Although OPU and RPU have the same repeating units and compositions, OPU may have a better ability to dampen the internal thermal energy owing to the more regulated secondary structure and hydrogen bonds. The main chain conformation and interchain interactions have important roles in the thermal stability of the polymers.

\section{High-temperature FTIR and H-bond analysis of OPU}

Thermal FTIR was performed to confirm the conformation and hydrogen bonding analyses. As shown in Figure 8a, the elevated temperature initially induced the collapse of the hydrogen bonds, and the absorption of aggregated $\mathrm{N}-\mathrm{H}$ groups at $\sim 3290 \mathrm{~cm}^{-1}$ were blue-shifted to high frequencies. The quantity of free $\mathrm{N}-\mathrm{H}$ groups increased gradually. Thermal degradation occurred until nearly all of the hydrogen bonded $\mathrm{N}-\mathrm{H}$ groups transformed to free groups, which is consistent with the TG curves. Furthermore, the intensities of the bands decreased in this process, which is characteristic of hydrogen bonding. In addition, the frequency of the peak at $1640 \mathrm{~cm}^{-1}$, which corresponded to the $\mathrm{C}=\mathrm{O}$ groups, increased as the temperature increased because the hydrogen bonded $\mathrm{N}-\mathrm{H}$ groups were associated with the $\mathrm{C}=\mathrm{O}$ groups from -NHCOO-. Intermolecular forces efficiently maintained the aggregations of macromolecules during heating, which improved the thermal stability of the polymers.

An orderly packed macromolecular backbone accompanied by hydrogen bonding can have a significant impact on the thermophysical properties of materials. ${ }^{22}$ Helical stereostructures with numerous hydrogen bonds exhibit a better ability to attenuate the thermal energy, which varies the vibration of the molecules and gives rise to infrared radiation. The infrared emissivity values of the samples at wavelengths of $8-14 \mu \mathrm{m}$ were investigated at room temperature. As listed in Table 3, RPU, which is based on racemic bisphenol, exhibits an infrared emissivity of 0.912 . After the introduction of chiral characteristics, the infrared emissivity value decreased to 0.785 , which demonstrates the hierarchical characteristics of OPU.

\section{CONCLUSIONS}

Bisphenols derived from chiral and racemic tyrosine were synthesized and then polymerized with MDI to produce the corresponding optically active and racemic PUs, respectively. The asymmetric force field in the chiral bisphenol induces a regular helical secondary structure in OPU, which exhibits a specific rotation of $-65^{\circ}$. The orderliness facilitates the construction of more hydrogen bonds in OPU, and both the hydrogen bonds and the regular helical secondary structure contribute to the improved crystallinity and thermal stability of the polymer. The thermophysical results indicate a lower infrared emissivity value for OPU compared with that of the random coiled RPU, which may provide a potential strategy for characterizing the assembly patterns of organic materials. Moreover, the introduction of chirality could be employed for various technological applications to provide enhanced performance.

\section{CONFLICT OF INTEREST}

The authors declare no conflict of interest.

\section{ACKNOWLEDGEMENTS}

We are grateful to the National Nature Science Foundation of China (51303083, 51077013), the Nature Science Foundation of Jiangsu Province (BK20130759) and the Scientific Research Foundation of the Nanjing University of Science and Technology (AE89903) for financial support.

1 Yashima, E. Synthesis and structure determination of helical polymers. Polym. J. 42 , 3-16 (2010).

2 Ho, R.-M., Chiang, Y.-W., Lin, S.-C. \& Chen, C.-K. Helical architectures from selfassembly of chiral polymers and block copolymers. Prog. Polym. Sci. 36, 376-453 (2011).

3 Leiras, S., Freire, F., Quinoa, E. \& Riguera, R. Reversible assembly of enantiomeric helical polymers: from fibers to gels. Chem. Sci. 6, 246-253 (2015).

4 Maeda, K., Wakasone, S., Shimomura, K., Ikai, T. \& Kanoh, S. Chiral amplification in polymer brushes consisting of dynamic helical polymer chains through the long-range communication of stereochemical information. Macromolecules 47, 6540-6546 (2014).

5 Zhu, Z., Cui, J., Zhang, J. \& Wan, X. Hydrogen bonding of helical vinyl polymers containing alanine moieties: a stabilized interaction of helical conformation sensitive to solvents and pH. Polym. Chem. 3, 668-678 (2012)

6 Hadano, S., Kishimoto, T., Hattori, T., Tanioka, D., Teraguchi, M., Aoki, T., Kaneko, T. Namikoshi, T. \& Marwanta, E. Helix-sense-selective polymerization of achiral bis (hydroxymethyl)phenylacetylenes bearing alkyl groups of different lengths. Mater. Chem. Phys. 210, 718-727 (2009).

7 Fu, Z., Xi, X., Jiang, L. \& Shen, Z. Optically active polymethacrylamides bearing a bulky oxazoline pendant: Synthesis and characterization. React. Funct. Polym. 67, 636-643 (2007).

8 Sudha, Kumar, D. \& Iwamoto, M. Investigation of the chiroptical behavior of optically active polyaniline synthesized from naturally occurring amino acids. Polym. J. 45, 160-165 (2013)

9 Zia, K. M., Bhatti, H. N. \& Bhatti, I. A. Methods for polyurethane and polyurethane composites, recycling and recovery: A review. React. Funct. Polym. 67, 675-692 (2007)

10 Szycher, M. Szycher's Handbook of Polyurethanes, (CRC Press, Boca Raton, FL, USA, 1999).

11 Ye, F., Quu, F., Yang, D., Cao, G., Guan, Y. \& Zhuang, L. Preparation and thermo-optic switch properties based on chiral azobenzene-containing polyurethane. Opt. Laser Technol. 49, 56-63 (2013).

12 Varkey, E. C. \& Sreekumar, K. Optical and thermal properties of diethyl-(2R, 3R) (+)-tartrate based chiral polyurethanes with main chain amido chromophores. J. Appl. Polym. Sci. 119, 111-119 (2011).

13 Yang, Y., Zhou, Y., Ge, J., Wang, Y. \& Chen, X. Synthesis, characterization and infrared emissivity property of optically active polyurethane derived from tyrosine. Polymer $\mathbf{5 2}$, 3745-3751 (2011).

14 Kohn, J. \& Langer, R. Polymerization reactions involving the side-chains of alpha-L-amino acids. J. Am. Chem. Soc. 109, 817-820 (1987).

15 Mattia, J. \& Painter, P. A comparison of hydrogen bonding and order in a polyurethane and poly(urethane-urea) and their blends with poly(ethylene glycol). Macromolecules 40, 1546-1554 (2007).

16 Oprea, S. Synthesis and characterization of polyurethane urea acrylates: effects of the hard segments structure. J. Appl. Polym. Sci. 105, 2509-2515 (2007).

17 Shahmohammadi, M.-H., Hajipour, A.-R. \& Habibi, S. Preparation and characterization of new optically active poly(amide-imide)s and poly(ester-imide)s containing Calix[4] arene units. Polym. Sci. Ser. B 56, 837-847 (2014).

18 Sogawa, H., Terada, K., Masuda, T. \& Sanda, F. Synthesis and properties of amino acid-derived optically active photo-responsive polymers. Polym. Bull. 63, 803-813 (2009)

19 Mallakpour, S. \& Zadehnazari, A. Advances in synthetic optically active condensation polymers - a review. Express Polym. Lett. 5, 142-181 (2011).

20 Zhang, H. \& Pu, L. Synthesis of helical polybinaphthyls. Macromolecules 37, 2695-2702 (2004)

21 Mallakpour, S. \& Rafiemanzelat, F. Preparation and properties of new copoly(amideimideether-urethane)s based on bis( $\mathrm{p}$-amido benzoic acid)-N-trimellitylimido-L-leucine by two different polymerization methods. Polym. Bull. 58, 339-350 (2007).

22 Wang, Z., Zhou, Y., Sun, Y. \& Yao, Q. Optically active helical polyurethane-urea with single-handed conformation for infrared low emissivity. Macromolecules 42, 4972-4976 (2009). 